\title{
Neuropsychological Correlates of Pre-Frailty in Neurocognitive Disorders: A Possible Role for Metacognitive Dysfunction and Mood Changes
}

\author{
Martina Amanzio ${ }^{1,2}$, Sara Palermo ${ }^{1 *}$, Milena Zucca ${ }^{3}$, Rosalba Rosato ${ }^{1,4}$, Elisa Rubino \\ Daniela Leotta ${ }^{5}$, Massimo Bartoli ${ }^{1}$ and Innocenzo Rainero ${ }^{3}$ \\ 'Department of Psychology, University of Turin, Turin, Italy, ${ }^{2}$ European Innovation Partnership on Active and Healthy \\ Ageing, Brussels, Belgium, ${ }^{3}$ Department of Neuroscience "Rita Levi Montalcini", University of Turin, Turin, Italy, ${ }^{4}$ Unit of \\ Cancer Epidemiology, "Città della Salute e della Scienza" Hospital and CPO Piemonte, Turin, Italy, ${ }^{5}$ Neurology Division, \\ Martini Hospital, Turin, Italy
}

OPEN ACCESS

Edited by:

Giuseppe Liotta,

Università degli Studi di

Roma Tor Vergata, Italy

Reviewed by:

Marco Canevelli,

Sapienza Università di

Roma, Italy

Giuseppe Bellelli,

Università degli studi di

Milano Bicocca, Italy

${ }^{*}$ Correspondence:

Sara Palermo

sara.palermo@unito.it

Specialty section: This article was submitted to Geriatric Medicine,

a section of the journal

Frontiers in Medicine

Received: 03 July 2017 Accepted: 31 October 2017 Published: 15 November 2017

Citation:

Amanzio M, Palermo S, Zucca M, Rosato R, Rubino E, Leotta D, Bartoli M and Rainero I (2017)

Neuropsychological Correlates of Pre-Frailty in Neurocognitive

Disorders: A Possible Role for Metacognitive Dysfunction and Mood Changes.

Front. Med. 4:199.

doi: 10.3389/fmed.2017.00199
Background: Recent studies have suggested that cognitive functions in patients with neurocognitive disorders have a significant role in the pathogenic mechanisms of frailty. Although pre-frailty is considered an intermediate, preclinical state, epidemiological research has begun to dislodge cognition and frailty into their specific subcomponents to understand the relationship among them. We aim to analyse the possible association between pre-frailty and neuropsychological variables to outline which factors can contribute to minor and major neurocognitive disorders.

Methods: 60 subjects complaining of different cognitive deficits underwent a deepin-wide frailty and neuropsychological assessment. We conducted three multiple linear regression analyses adjusted for a combination of demographic measures and involving several neuropsychological-behavioural parameters selected by the literature on physical frailty.

Results: We found a significant association between frailty-as measured by the multidimensional prognostic index (MPI) - and action monitoring and monetary gain (cognitive domain), depression and disinhibition (behavioural domain). Moreover, an association between MPI and impaired awareness for instrumental activities disabilities exists.

Conclusion: We propose a novel framework for understanding frailty associated with metacognitive-executive dysfunction.

Keywords: pre-frailty, mild cognitive impairment, comprehensive geriatric assessment, Alzheimer's disease, executive dysfunction

\section{INTRODUCTION}

Frailty is a complex and heterogeneous clinical syndrome. It is described by augmented vulnerability resulting from age-related decline across several body organs and physiological systems $(1,2)$. Frailty leads to a decrease in the ability to remain independent and to maintain a good quality of life (3). Moreover, it increases the risk of disability and mortality (3). The frailty syndrome has principally 
been explored by focussing on the physical domain, mostly relying on signs and symptoms such as muscle weakness, sedentary behaviour, slow gait speed, and weight loss (1). Frailty has also been involved in general cognitive decline and impaired global cognition (4).

Canevelli and colleagues (5) have recently emphasised some criticalities of these studies: (a) the overwhelming majority of them have assessed frailty using the criteria proposed by Fried and colleagues (1), primarily aimed at describing the physical dimension of frailty; (b) most of these researches adopted only a measure of global cognitive functioning, mostly assessed by the Mini Mental State Examination [MMSE; (6)] to assess cognition, in absence of a comprehensive neuropsychological evaluation; (c) finally, the sample populations were mainly composed of community-dwelling older adults, preventing the applicability of results to other types of patients. The limitations of those studies have also been previously reported (7).

The overall concept of examining the specific cognitive correlates of frailty is interesting and may indeed shed light on a more comprehensive model of frailty that details a specific neuropsychological profile. Interestingly, the most novel evidence comes from a small number of studies aimed at examining the association between specific cognitive functions and physical frailty (5). In particular, Canevelli and colleagues (5) pointed out a significant impairment of attention and executive functions. Importantly, literature has shown that the executive function and attention domains are related to frailty, while gait speed or grip strength are the components of frailty most strongly associated with cognition (8-20). O'Halloran and colleagues (8) recently stated that pre-frail and frail individuals seem less able than robust subjects in the "Sustained Attention to Response Task" (SART). Even if these studies represent a first important attempt to describe the association between cognitive functions and physical frailty, there is still the need to assess frailty with a multidimensional approach (21-23).

Although executive function and attention domains may be related to physical frailty, no previous studies have investigated the role of different neuropsychological domains by carrying out a multidimensional assessment of frailty. In line with this, the multidimensional prognostic index (MPI) currently represents one of the suggested methods for a comprehensive assessment of frailty (24-26).

The aim of this study is to investigate whether pre-frailty, measured through the MPI, might be influenced by cognitivebehavioural measures in individuals with minor and major neurocognitive disorders [DSM-5; (27)], from mild cognitive impairment (MCI) likely due to Alzheimer's disease (AD), to mild AD patients (28). For this reason, we conducted three multiple linear regression analyses to study: (1) the role of global cognitive functioning and specific cognitive variables (selective attention, episodic memory, language comprehension, and reasoning in the visual modality); (2) the role of metacognitive executive functions, such as response monitoring; and (3) the relationship with mood changes, quality of life, and awareness of independence for daily living instrumental activities.

\section{MATERIALS AND METHODS}

\section{Participants}

All the outpatients were enrolled at the Neurology Division of the "Città della Scienza e della Salute" Hospital and the Martini Hospital, both in Turin (Italy).

Participants were included in the study if they had: (a) minor or major neurocognitive disorders (27), such as MCI-likely due to $\mathrm{AD}$ and mild $\mathrm{AD}$. On the other hand, participants were excluded from the study if they had: (a) dysthymia or major depressive disorder, based on DSM-5 criteria (27); (b) A MMSE score $<20$, given that the neuropsychological measurement is not as reliable when problems of language comprehension occur; (c) were taking medications that could substantially impact cognitive functioning. CSF diagnosis that did not provide in vivo evidence of Alzheimer's pathology was considered exclusion criterion.

The patients underwent a complete neurological examination and neuroradiological investigations (MRI and FDG-PET). All the patients underwent lumbar puncture with cerebrospinal fluid measurement of 1-42 beta-amyloid, phospho-Tau, and total-Tau (Innogenetics kits, Ghent, Belgium).

\section{Assessment of Frailty}

Several operational definitions have been proposed to assess frailty in the elderly (29). Although this variability might be acceptable from a public health perspective, the identification of a gold standard measure might still be important to obtain. To date, frailty is still detected using different instruments and none of them has been able to prevail as superior to the others (29).

An index originally conceived and designed in the Italian general practice setting for the evaluation of chronic multipathological conditions was initially used to screen the participants' levels of frailty (30). The scale for the Evaluation of the frailty elderly (Scheda di Valutazione dell'Anziano Fragile, ${ }^{1}$ SVAFRA) is a "multiaxial" score, interpreted according to the principles of the complexity theory in medicine and healthcare (30). This scale is a useful tool in case of multiaxial assessment in the setting of primary care (31), especially for its ability to combine technical skills, synthesis of information, and caremanagement suggestions $(30,31)$. SVAFRA was used for the first "Cognitive survey on the frailty of elderly people in Italy," which was attended by 34 Primary Care Physicians and 521 elderly recruited in Veneto, Lazio, and Sicily (32).

According to the authors, frailty is determined by issues pertaining at least one of the following evaluative dimensions (30): physical and mental health; physical and cognitive-behavioural disabilities; patient management considering the care burden; family and socio-environmental background. For each axis, determinants can assume a value between 0 (no deficiencies) and 3 (very serious problems). The level of frailty is then classified based on a combination of these four dimensions. A synthetic value-regardless of the value previously assigned to the four determinants — can also be assigned: F0 (absence of frailty, typical

${ }^{1}$ Frailty in the elderly evaluation sheet. 
of healthy patients); F1 (pre-frailty); F2 (medium frailty); F3 (severe frailty, typical of severely ill patients); T (extreme frailty, typical of terminally ill patients).

Since clinicians needed an outcome instrument with sound clinimetric properties (33), frailty was assessed using a comprehensive geriatric assessment (CGA), which was considered the first-choice tool for evaluating biological, functional, cognitive, social, and clinical aspects of elderly subjects, as expressed by the Italian Society of Gerontology and Geriatrics $(34,35)$. The MPI was developed from a standardised CGA $(26,35,36)$. It was originally conceived as a prognostic index of mortality in the short- and long-term period based on information obtained through the CGA in hospitalised (37) and outpatient settings (38). With this index, the prognostic value of negative outcomes and related severity are even higher than with the indices calculated in the single domains of the rating. The MPI is also considered suitable for assessing frailty in the elderly (34-36). Moreover, as a cumulative multidimensional index, the MPI allows professionals to develop a treatment plan (22). In 2013, the European Innovation Partnership on Active and Healthy Ageing identified 98 "good practices" involved in research to reverse or prevent frailty (24). As demonstrated by the Marco Polo Initiative, the MPI is helpful in identifying frailty elders, providing personalised interventions, avoiding drug prescriptions and adverse hospital admissions $(24,39)$.

The MPI includes information on clinical, functional, nutritional, and neuropsychological aspects, as well as polypathology, pharmacological treatment, and the social support network (22, 25, 26, 35-40). Specifically, the MPI is calculated using a mathematical algorithm that includes scores of individual profiles obtained from the eight evaluation tools that make up the CGA: 1. activity of daily living scale (ADL); 2. instrumental activity of daily living scale (iADL); 3. short portable mental status questionnaire (to assess cognitive status); 4. cumulative illness rating scale-comorbidity index (CIRS-CI, to explore comorbidity); 5. Mini Nutritional Assessment scale (MNA, to assess nutritional status); 6. Exton Smith Scale (to evaluate the risk of developing pressure sores); 7. polypharmacy; 8. social condition (22, 25, 26, 35-40).

The numerical index obtained has a value between 0.0 (lowest risk) and 1.0 (highest risk of mortality) and reports three grades of risk of severe prognosis: low risk (MPI value $\leq 0.33$ ), moderate risk (MPI value between 0.34 and 0.66 ), and severe risk $(M P I \geq 0.67)(22,26,36,37,40)$. Importantly, the effectiveness of the MPI has recently been verified in population-based cohorts. Higher MPI risk scores were associated with more days in hospital and with fewer years of survival, across a broad and stratified age range $(25,40)$.

\section{Neuropsychological Assessment}

The neuropsychological evaluation involved a wide assessment of global cognitive deterioration using: the CDR (41), the Addenbrooke's Cognitive Examination-Revised version [ACE-R; (42)] and, finally, the MMSE (6). Other cognitive domains were also assessed with the use of different scales: selective attention with Attentional Matrices [AM; (43)], divided attention and cognitive shifting with the Trial Making Test [TMT; $(43,44)$ ], episodic memory with the Recall of a Short Story test [Babcock; (37)], reasoning in the visual modality with Coloured Progressive Matrices [CPM-36; (43)], comprehension of spoken language with the Token Test [TT; $(43,45)]$.

Executive functions were analysed with the metacognitive version of the Wisconsin Card Sorting Test [m-WCST; $(46,47)$ ]. This test is aimed to assess "on-line" metacognitive monitoring and control during the execution of the test $(46,47)$. For each card of the test, two questions evaluated "on-line" metacognitive monitoring ("What is your degree of confidence in this answer?") and control ("Do you want to take this response into account in your total score?") (46-48). In the original version of Koren's protocol, the participants were assigned a dollar value for each correct response (46-48). In this study, the patients received a monetary gain of 10 cents for each correct answer and they were deprived of 10 cents for every wrong answer (49). As described in our previous work that used the same procedure (49), a set of metacognitive indices were evaluated: “(1) accuracy score (AS), the number of correct voluntary answers/ number of voluntary responses; (2) free choice improvement (FCI) (accuracy-number of correct responses from forced responses)/number of cards presented; (3) global monitoring (GM), the number of correct responses-the total number of sorts required in the final score; (4) monitoring resolution (MR), the gamma correlation calculated between the confidence and correctness of the sorts in the entire test; (5) control sensitivity (CS), to what extent the control process depended on the monitoring process, indexed by the gamma correlation calculated across all sorts between the level of confidence and the decision to gamble; (6) monetary gains (MG), given by the number of correct voluntary responses-incorrect number of voluntary responses" [(49), p. 138].

We verified the subjects' level of autonomy in basic and instrumental activities of daily living $(50,51)$ and accordingly, their quality of life with the Quality of life scale in Alzheimer's disease (QoL-AD) - patient's subscale (52). Patients were also assessed using specific neuropsychiatric rating scales of mood changes: apathy and depression with Hamilton Depression Rating Scale [HDR-S; (53)], disinhibition and hypomania with the Disinhibition Scale and the Mania Scale [DIS-S (54); MAS (55)].

Finally, in accordance with what we did in our previous work (56), "we followed the classification of Starkstein and colleagues (57) who used principal component analysis to subdivide the Awareness of Deficit Questionnaire-Dementia scale [AQD (58)] into four domains taking into consideration the factors loading on each item. One of these factors, identified in terms of impaired awareness in instrumental activities of daily living (AQD_iADL), was designated as factor 1 by the authors. Factor 1 embraces 12 items: 'recalling the date, orienting to new places, recalling telephone calls, remembering the location of objects at home, understanding conversation and the plot of a movie, keeping belongings in order, handling money, doing mental calculations, remembering shopping lists and appointments, performing clerical work.' Thus it accounted for most of the variance and also rated as the earliest functional deficit in patients with cognitive impairment" [(56), p. 65]. Since disabilities in 
instrumental activities of daily living were one of the descriptors of frailty used in the Canadian Study on Health and Ageing (59), we decided to take it into consideration in our analyses.

\section{Procedures}

We implemented a cross-sectional study to explore data collected from our clinical population. Patients were evaluated by performing a neuropsychological assessment during a week in hospital. The participants were assessed in three experimental sessions held 1 day apart and each lasting $1 \mathrm{~h}$, with a view to preventing fatigue and lack of adherence to the tasks.

\section{Statistical Analysis}

We performed statistical analyses using SAS/STAT ${ }^{\circledR} 9.3(60,61)$. The post hoc power was determined using the formula for sample size with continuous measures through $\mathrm{G}^{\star}$ Power 3 , which is a stand-alone power analysis tool for statistical tests commonly used in social and behavioural research (62). The achieved power with a sample size of 60 was estimated to provide a minimum of $70 \%$ power at a $5 \%$ level of significance (two-sided) to detect a medium effect $\left(r^{2}=0.2\right)$.

To study whether the level of the MPI index could be associated with cognitive and behavioural measurements, we conducted three multiple linear regression analyses adjusted for age, gender, and schooling. Normality assumption distribution of linear regression model residuals was evaluated by means of the Kolmogorov-Smirnov test.

Importantly, the selection of the three models was performed in line with the results obtained in the literature on physical frailty. In particular, frailty has been previously associated with general cognitive decline, impaired global cognition, and memory $(5,8,18)$. Moreover, executive function and attention domains have been consistently related to frailty $(8-10,12-20)$. Finally, the association between physical frailty and the performance at the SART test (8) seems to suggest that pre-frail and frail people might be impaired in response monitoring.

The final selected models considered the MPI as the dependent variable and the following as independent variables:

- Model (1) to address the role of global cognitive functioning and specific cognitive variables (selective attention, episodic memory, language comprehension, and reasoning in the visual modality): ACE-R, MA, BABCOCK, TT and CPM-36;

- Model (2) to study the role of metacognitive executive functions with m-WCST: FCI, GM, MR, and MG;

- Model (3) to investigate the relationship with mood changes, quality of life and awareness of autonomy in instrumental activities of daily living: HDR-S, MAS, DIS-S, QOL-AD, and AQD_iADL.

\section{RESULTS}

Over a 24-month period, 72 patients-complaining of different cognitive deficits and presenting for the first time at the out-dep of our clinics-were evaluated with the overall neuropsychological assessment. After a month, based on CSF analysis results, only subjects with an $\mathrm{AD}$-compatible liquor were included in the experimental sample. As a result, 12 patients were excluded, while 60 subjects were enrolled. Based on the exclusion criterion, 12 patients were excluded, while 60 subjects $(M / F=22 / 38$; mean age $\pm \mathrm{SD}=69.6 \pm 6.8$ years) were enrolled (see Table 1 for demographic and clinical data). In particular, $24 \mathrm{MCI}$ due to $\mathrm{AD}$ patients according to the CSF analysis, were included in the study. For those patients with major neurocognitive disorders, the CSF diagnosis provided in vivo evidence of Alzheimer's pathology for 36 patients. The neuropsychological assessment reflected the diagnoses made by the CSF (see Table 2 and Table S1 in Supplementary Material), biomarkers and neurological exams. Fifty-six of the 60 patients obtained a CDR score of between 0 and 1 attesting a low level of cognitive impairment.

\section{Prevalence of Frailty Status}

As regard the CGA evaluation, the patients fell within the lowest MPI range, attesting a low risk of severe prognosis. Considering the SVAFRA index, 97\% of all patients were classified as pre-frail, and 3\% with medium frailty.

\section{Association between Frailty and Neuropsychological Variables}

After adjusting the analysis for age, gender, and schooling, the MPI index scores were influenced by MR and MONEY in model 2, and by HDR-S, DIS-S, and AQD_iADL in model 3. On the contrary, the level of pre-frailty measured through the MPI index was not influenced by global cognition, memory,

TABLE 1 | Demographic characteristics and frailty evaluation by a comprehensive geriatric assessment.

\begin{tabular}{|c|c|c|c|}
\hline & $\begin{array}{l}\text { Maximum } \\
\text { scores }\end{array}$ & Mean \pm SD & Cutoff \\
\hline \multicolumn{4}{|l|}{ Demographic characteristics } \\
\hline Gender (male/female) & & $22 / 38$ & \\
\hline Age (years) & & $66.62 \pm 6.80$ & \\
\hline Schooling (years) & & $9.28 \pm 3.86$ & \\
\hline $\begin{array}{l}\text { Early cognitive symptoms } \\
\text { complaints (months) }\end{array}$ & & $31.15 \pm 27.82$ & \\
\hline Clinical dementia rating scale & & $0.78 \pm 0.44$ & \\
\hline \multicolumn{4}{|l|}{ Multidimentional prognostic index } \\
\hline Activity of daily living scale & 8 & $5.70 \pm 0.53$ & $\geq 4$ \\
\hline $\begin{array}{l}\text { Instrumental activity of daily } \\
\text { living scale }\end{array}$ & 6 & $6.63 \pm 1.55$ & $\geq 6$ \\
\hline $\begin{array}{l}\text { Short portable mental state } \\
\text { questionnaire }\end{array}$ & 10 & $2.46 \pm 1.63$ & $\leq 2$ \\
\hline $\begin{array}{l}\text { Cumulative illness rating } \\
\text { scale-comorbidity index }\end{array}$ & 13 & $1.43 \pm 1.42$ & \\
\hline Mini nutritional assessment & 30 & $21.32 \pm 3.62$ & $\geq 24$ \\
\hline Exton Smith Scale & 20 & $18.80 \pm 1.47$ & $\geq 15$ \\
\hline Polypharmacy & & $4.12 \pm 2.46$ & \\
\hline Social condition & & Household & \\
\hline Multidimensional prognostic index & 1 & $0.19 \pm 0.12$ & \\
\hline \multicolumn{4}{|l|}{ SVAFRA $^{a}$} \\
\hline $\mathrm{F} 1$ & & $\%=97$ & \\
\hline $\mathrm{F} 2$ & & $\%=3$ & \\
\hline
\end{tabular}

Wherever there is a normative value, the cutoff scores are given in the statistical normal direction. Cells in grey indicate the absence of a normative cutoff.

aScheda di Valutazione dell'Anziano Fragile. 
TABLE 2 | Neuropsychological and neuropsychiatric assessment synopsis.

\begin{tabular}{|c|c|c|c|}
\hline & $\begin{array}{l}\text { Maximum } \\
\text { scores }\end{array}$ & Mean \pm SD & Cutoff \\
\hline \multicolumn{4}{|l|}{ Neuropsychological assessment } \\
\hline Mini-mental state examination & 30 & $25.02 \pm 2.85$ & $\geq 24$ \\
\hline $\begin{array}{l}\text { Addenbrooke's cognitive } \\
\text { examination - revised version }\end{array}$ & 100 & $69.57 \pm 12.60$ & $\geq 82$ \\
\hline Attentional matrices & 60 & $30.52 \pm 9.91$ & $\geq 31$ \\
\hline Trial making test $A$ & 500 & $110.73 \pm 82.92$ & $\leq 94$ \\
\hline Trial making test $\mathrm{B}$ & 500 & $297.18 \pm 158.12$ & $\leq 283$ \\
\hline Trial making test B-A & & $194.92 \pm 127.11$ & $\leq 187$ \\
\hline Babcock & 16 & $6.22 \pm 3.72$ & $\geq 4.75$ \\
\hline Coloured progressive matrices-36 & 36 & $22.17 \pm 7.26$ & $\geq 18.96$ \\
\hline Token test & 36 & $30.21 \pm 3.61$ & $\geq 32.69$ \\
\hline $\begin{array}{l}\text { Wisconsin card sorting test \% } \\
\text { correct answers }\end{array}$ & & $52.59 \pm 15.44$ & $\geq 37.1$ \\
\hline $\begin{array}{l}\text { Wisconsin card sorting test \% } \\
\text { perseverative errors }\end{array}$ & & $34.34 \pm 14.95$ & $\leq 42.7$ \\
\hline \multicolumn{4}{|l|}{$\begin{array}{l}\text { Wisconsin card sorting } \\
\text { test-metacognitive version }\end{array}$} \\
\hline Accuracy score & & $0.03 \pm 0.11$ & \\
\hline Free choice improvement & & $-1.17 \pm 4.98$ & \\
\hline Global monitoring & & $-20.13 \pm 14.29$ & \\
\hline Monitoring resolution & & $0.19 \pm 0.24$ & \\
\hline Control sensitivity & & $-0.04 \pm 0.58$ & \\
\hline Monetary gains & & $2.37 \pm 1.93$ & \\
\hline \multicolumn{4}{|l|}{ Neuropsychiatric assessment } \\
\hline $\begin{array}{l}\text { Quality of life scale in Alzheimer's } \\
\text { disease-patient module }\end{array}$ & 39 & $17.90 \pm 8.01$ & \\
\hline Hamilton depression rating scale & 67 & $10.95 \pm 7.47$ & $\leq 7$ \\
\hline Disinhibition scale & 96 & $9.40 \pm 6.95$ & $\leq 16.9$ \\
\hline Mania scale & 44 & $2.62 \pm 3.57$ & $\leq 15$ \\
\hline $\begin{array}{l}\text { Awareness of deficit questionnaire- } \\
\text { dementia scale for instrumental } \\
\text { activity domain }\end{array}$ & 16 & $3.20 \pm 8.22$ & $\leq 4$ \\
\hline
\end{tabular}

Wherever there is a normative value, the cutoff scores are given in the statistical normal direction. Cells in grey indicate the absence of a normative cutoff. language comprehension, non-verbal reasoning (in model 1), or by QOL-AD (in model 3, see Table 3).

The normality distribution assumption of residuals in each model is fulfilled (Kolmogorov-Smirnov test $>0.05$ ).

\section{DISCUSSION}

The aim of this study was to analyse the association among a multidimensional assessment of frailty, executive dysfunction and specific cognitive and behavioural variables using an overall neuropsychological battery. Our findings suggested that pre-frailty was associated with metacognitive executive dysfunction, in terms of action monitoring in MCI-likely due to $\mathrm{AD}$ and $\mathrm{AD}$ patients. Specifically, we observed a significant association between the MPI index and MR underlying the role of MR, where patients fail to distinguish between correct and incorrect sorts. The results obtained were specific and not influenced by other cognitive functions such as global cognition, memory, language comprehension, and non-verbal reasoning, with the exception of the selective attention task that reached a near significance level. Moreover, taking the MPI scores into account, we observed an involvement of mood changes in terms of depression, apathy, and disinhibition and a reduced awareness of iADL, while the relationship with hypomania was near to the significance value.

Although we considered patients with different degrees of cognitive impairment, our sample was homogeneous in terms of the etiopathogenesis, MPI level of risk, comorbidity with physical illness, somatic complaints, laboratory tests, and the level of mood changes. Moreover, we excluded all patients with neurological diseases other than AD. Most importantly, our attempt to consider these kinds of patients in the same sample was justified by the regression analysis approach we used and by

TABLE 3 | Effect of the independent variables on the multidimensional prognostic index estimated by the univariate and multiple linear regression analyses.

\begin{tabular}{|c|c|c|c|c|c|c|c|}
\hline \multirow[b]{2}{*}{ Model } & \multirow[b]{2}{*}{ Independent variables } & \multicolumn{3}{|c|}{ Crude estimates } & \multicolumn{3}{|c|}{ Adjusted estimates } \\
\hline & & $\beta$ & $p$ & SE & $\beta$ & $p$ & SE \\
\hline \multirow[t]{6}{*}{1} & Addenbrooke's cognitive examination - revised version & -0.20 & 0.18 & 0.001 & -0.03 & 0.87 & 0.001 \\
\hline & Attentional matrices & -0.36 & 0.02 & 0.002 & -0.29 & 0.11 & 0.002 \\
\hline & Babcock & -0.05 & 0.75 & 0.005 & 0.09 & 0.60 & 0.006 \\
\hline & Token test & -0.12 & 0.43 & 0.005 & -0.01 & 0.95 & 0.005 \\
\hline & Coloured progressive matrices-36 & -0.27 & 0.06 & 0.002 & -0.14 & 0.44 & 0.003 \\
\hline & Model significance & \multicolumn{6}{|c|}{$R^{2}=0.2056, F=1.42 p=0.2137$} \\
\hline \multirow[t]{5}{*}{2} & Free choice improvement & 0.07 & 0.60 & 0.003 & 0.03 & 0.84 & 0.003 \\
\hline & Global monitoring & -0.07 & 0.60 & 0.001 & 0.11 & 0.42 & 0.001 \\
\hline & Monitoring resolution & 0.33 & 0.02 & 0.075 & 0.37 & 0.01 & 0.073 \\
\hline & Monetary gains & -0.21 & 0.14 & 0.009 & -0.30 & 0.04 & 0.009 \\
\hline & Model significance & \multicolumn{6}{|c|}{$R^{2}=0.2863, F=2.46 p=0.0322$} \\
\hline \multirow[t]{6}{*}{3} & Hamilton depression rating scale & 0.49 & $<0.00$ & 0.002 & 0.41 & $<0.00$ & 0.002 \\
\hline & Mania scale & 0.09 & 0.52 & 0.005 & -0.25 & 0.07 & 0.005 \\
\hline & Disinhibition scale & 0.50 & $<0.00$ & 0.002 & 0.52 & $<0.00$ & 0.003 \\
\hline & Quality of life scale in Alzheimer's disease & -0.21 & 0.17 & 0.002 & -0.01 & 0.91 & 0.002 \\
\hline & AQ-D scale for instrumental activity domain & -0.14 & 0.35 & 0.002 & -0.30 & 0.02 & 0.002 \\
\hline & Model significance & \multicolumn{6}{|c|}{$R^{2}=0.4980, F=5.46 p<0.0001$} \\
\hline
\end{tabular}

In multivariable analyses standardised coefficients are adjusted for age, gender, and schooling. Values in bold italics showed a statistically significant association ( $p$ < 0.05).

$A Q-D$, Awareness Questionnaire in Dementia. 
the international guidelines on ageing that consider patients with cognitive impairment to lie on a continuum between MCI and mild $\operatorname{AD}(28,63,64)$.

Based on the results we obtained, there appear to be no straightforward associations between pre-frailty and specific aspects of neuropsychological functioning such as global cognition, long-term verbal memory, language comprehension, and non-verbal reasoning. As underlined by a review on cognitive impairment and frailty, not all cognitive domains may become impaired simultaneously (7). Although Canevelli et al. (5) have described a possible association between memory and physical frailty, other studies have found that memory does not seem to be clearly associated with frailty [i.e., Ref. $(17,65)]$. As far as we are aware, no previous studies have addressed the association between frailty and language comprehension on the one hand, and frailty and non-verbal reasoning on the other (18). Moreover, we found no generalised cognitive impairment as a prerequisite of pre-frailty in our patients. Nevertheless, previously researches have reported a substantial association between frailty and cognitive deterioration $(5,7,18,66)$, although the phenotype model often used in these does not include cognitive function in its definition (1). Despite these evidences-as previously suggested by Robertson and colleagues (7) - statistical analyses of the proposed components of frailty suggest that, while energy, mobility, mood, physical activity, and strength aggregate as one concept, cognitive function does not clearly correlate with this and therefore may not be part of the frailty syndrome $(67,68)$. Furthermore, a study of AD patients found that $22 \%$ had no indications of frailty $(69,70)$. Indeed, Fougère and colleagues in their review concluded that "it seems most useful, therefore, to treat frailty and cognitive impairment as related but distinct concepts that frequently co-occur" [(71), p. 3].

Notably, the assessment of executive dysfunction should be seen as an important early predictor of cognitive frailty (9), since these problems may appear as the first cognitive changes in MCI patients (72), with concomitant iADL difficulties (73). Indeed, the early identification of executive impairments may be helpful for predicting the long-term functional outcome (74). Interestingly, O'Halloran and colleagues (8) recently stated that pre-frail and frail individuals seem to make more commission errors and omissions than robust subjects on the SART that evaluates the ability to sustain attention for a long time with a response-suppression element $(75,76)$. This fact suggests that they may be impaired in response monitoring, as we have demonstrated through the association between pre-frailty and action monitoring using the m-WCST. Indeed, the main predictor at this level has been MR, expressed by Koren and colleagues as the correlation between the level of confidence expected from the response and correctness of the sorts in the entire WCST (46-48). In particular, our patients have shown failure to monitor their own performance considering the errors made during task execution, in terms of low metacognitive self-awareness. Moreover, we have found an association between the MPI and monetary gain, which can be interpreted as subjects' ability to benefit from environmental feedback, anticipate the consequences of their future actions and make decisions accordingly. In addition, we have also found pre-frailty to be associated with an inability to report unsuccessful experiences in iADL through the Awareness Questionnaire in Dementia (AQ-D) (56). In our previous article concerning impaired awareness of deficits in $\mathrm{AD}$ and the role of everyday executive dysfunction (56), mood orientation changes, inhibition, self-monitoring, and set shifting appeared to be important skills for awareness of iADL (AQD_iADL) (56). According to this and considering the neural substrate, AD patients with impaired awareness showed reduced activation in the Mid Cingulate Cortex during an event-related fMRI response-inhibition paradigm, compared to subjects aware of their deficits (77).

Through our current results we hypothesise that pre-frailty may arise by a disruption of the comparator mechanisms responsible for monitoring behavioural mood changes and cognitive disturbances (56). If the executive system does not function properly, as frequently described in MCI-likely due to $\mathrm{AD}$ and $\mathrm{AD}$ patients (78), the comparator mechanism does not detect incongruities between the previous and the actual state of behaviour/performance. This phenomenon has been observed as an inability: (1) to monitor one's own performance with reference to the impact of errors made during task execution, in terms of a reduction in metacognitive self-awareness; and (2) to relate fruitless experiences in one's everyday living through the AQ-D.

The few studies investigating the neuropsychiatric factors (79-81) have suggested that "one mechanism underlying the link between frailty and cognition may be due to psychological factors such as mood. Indeed, mood disorders such as depression have been found to be both a risk factor for and a consequence of frailty" [(7), p. 847]. In line with this, we observed a role of HDR-S scores in pre-frailty condition. The HDR-S actually measures mood changes, in terms of apathetic behaviour and depressive mood possibly related to prefrontal dysfunctions (82). This evidence also suggests a possible role of apathy in pre-frailty conditions (83). Interestingly, apathy, disinhibition, and metacognitive executive dysfunction appear to be neurally inscribed in the same network (84-87). The results we obtained proposed the suggestive hypothesis that pre-frailty may be due to a possible dysfunction of the medial prefrontal-ventral striatal network observed throughout action-monitoring disability, mood changes, and reduced awareness of iADL. These findings ask for new neuroimaging investigations and replication in a larger group of patients.

\section{Limitations Section}

The study here presented has been carefully designed and reached its aims; however, some critical aspects have to be outlined. The first aspect regards the tools used to assess frailty, which could represent a possible confounding factor. In particular, pre-frailty is defined by adopting the SVAFRA that may not be considered appropriate for stratifying the frailty status of the older person and it has been rarely adopted for these purposes. Moreover, the MPI was originally conceived as a prognostic index of mortality in the short- and long-term period (37) and a recent international survey among clinical practitioners on the methods to assess frailty in their daily practice (29) did not include MPI as a tool to assess frailty. However, as previously expressed by Bruyére and colleagues (29), frailty is still detected using different 
instruments and none of them has been able to prevail as superior to the others (29). Second, the results we obtained are not generalisable for patients with different etiopathogenesis other than AD. However, our study is a first attempt to investigate possible association between pre-frailty and neuropsychological variables in a selected patient population, on the basis of liquor examination and may be limited to identify pathogenetic mechanisms of frailty. This is a cross-sectional study aimed to evaluate a possible association between frailty and neuropsychological variables in MCI-likely due to $\mathrm{AD}$ and $\mathrm{AD}$ patients. A longitudinal study may be the most correct approach to assess for the presence of cognitive disorders many years before the development of frailty itself. Further studies will be important to better characterised this association over time and replicate these findings in a larger group of patients.

\section{CONCLUSION}

This study represents a first important attempt to extend the frailty issue to neuropsychological correlates taking in consideration a multidimensional approach These findings suggest that the assessment of pre-frailty conditions must be achieved quantitatively by means of a multidimensional approach to clarify the nature and correlates of this multifaceted phenomenon. In particular, the impact of everyday executive dysfunction, early changes in mood and the awareness of iADL disabilities must be considered. Our results benefit from the homogeneity of the experimental sample in terms of etiopathogenetic mechanisms, disease severity (CDR) and functionality in daily life $(\mathrm{ADL} / \mathrm{iADL})$. The evaluation of pre-frailty conditions and their neuropsychological correlates is clinically relevant. Indeed, this multifaceted phenomenon has diagnostic, nosological, and prognostic implications that may affect patients' wellbeing in the continuum from MCI to AD.

\section{AUTHOR CONTRIBUTIONS}

The study is based on a concept developed by MA who wrote the paper and took part in the review and critique processes as PI. She also organised the study and participated in the statistical analyses (execution and organisation, review, and critique). SP

\section{REFERENCES}

1. Fried LP, Tangen CM, Walston J, Newman AB, Hirsch C, Gottdiener J, et al. Frailty in older adults: evidence for a phenotype. J Gerontol A Biol Sci Med Sci (2001) 56:M146-56. doi:10.1093/gerona/56.3.M146

2. Rockwood K, Mitnitski A. Frailty in relation to the accumulation of deficits. J Gerontol A Biol Sci Med Sci (2007) 62:722-7. doi:10.1093/gerona/ 62.7.722

3. Heuberger RA. The frailty syndrome: a comprehensive review. J Nutr Gerontol Geriatr (2011) 30:315-68. doi:10.1080/21551197.2011.623931

4. Matusik P, Tomaszewski K, Chmielowska K, Nowak J, Nowak W, Parnicka A, et al. Severe frailty and cognitive impairment are related to higher mortality in 12-month follow-up of nursing home residents. Arch Gerontol Geriatr (2012) 55:22-4. doi:10.1016/j.archger.2011.06.034

5. Canevelli M, Cesari M, van Kan GA. Frailty and cognitive decline: how do they relate? Curr Opin Clin Nutr Metab Care (2015) 18:43-50. doi:10.1097/ MCO.0000000000000133 performed the neuropsychological assessment (execution and organisation), participated in the statistical analyses, participated in writing the paper and created the infographics. RR conducted the statistical analyses (execution), participated in interpretation of results and in writing the paper. ER performed the neurological assessment (execution) and took part in the organisation of the study and in the diagnostic phase (organisation and diagnosis). MZ and MB performed the neuropsychological assessment (execution), participated in writing the paper and in drafting the work. DL and IR supervised the neurological assessment, took part in the organisation of the study and participated in writing the paper (organisation, review, and critique). All the contributors gave their approval of this version of the manuscript to be submitted.

\section{ACKNOWLEDGMENTS}

The study was approved by the Ethics Committee "A.O.U. Città della Salute e della Scienza di Torino-A.O. Ordine MaurizianoA.S.L. Città di Torino" as part of the core research criteria followed by the Neurological Units. All the implemented procedures ensured the safety, integrity, and privacy of patients. All subjects gave their informed written consent to participate in the study. As far as data regarding human biological samples are concerned, the cerebrospinal fluid acquisition procedures used are safe and fall within the scope of ordinary clinical-diagnostic routine practice. Finally, any critical aspects, neither with regard to the functionalneurocognitive assessment phase nor to the neuropsychological assessment could be noticed. Importantly, the study has been conducted according to the principles set forth by the Declaration of Helsinki (59th WMA General Assembly, Seoul, October 2008) and in accordance with the Medical Research Involving Human Subjects Act (WMO).

\section{SUPPLEMENTARY MATERIAL}

The Supplementary Material for this article can be found online at http://www.frontiersin.org/article/10.3389/fmed.2017.00199/ full\#supplementary-material.

TABLE S1 | CSF assessment synopsis. The results of all subjects are reported.

6. Folstein MF, Folstein SE, McHugh PR. "Mini-mental state". A practical method for grading the cognitive state of patients for the clinician. J Psychiatr Res (1975) 12:189-98. doi:10.1016/0022-3956(75)90026-6

7. Robertson DA, Savva GM, Kenny RA. Frailty and cognitive impairment. A review of the evidence and causal mechanisms. Ageing Res Rev (2013) 12:840-51. doi:10.1016/j.arr.2013.06.004

8. O'Halloran AM, Finucane C, Savva GM, Robertson IH, Kenny RA. Sustained attention and frailty in the older adult population. J Gerontol B Psychol Sci Soc Sci (2014) 69:147-56. doi:10.1093/geronb/gbt009

9. Delrieu J, Andrieu S, Pahor M, Cantet C, Cesari M, Ousset PJ, et al. Neuropsychological profile of "cognitive frailty" subjects in MAPT study. J Prev Alzheimers Dis (2016) 3:151. doi:10.14283/jpad.2016.94

10. Harley C, Wilkie RM, Wann JP. Stepping over obstacles: attention demands and aging. Gait Posture (2009) 29:428-32. doi:10.1016/j.gaitpost.2008.10.063

11. Hooghiemstra AM, Ramakers IHGB, Sistermans N, Pijnenburg YAL, Aalten P, Hamel REG, et al. Gait speed and grip strength reflect cognitive impairment and are modestly related to incident cognitive decline in memory clinic 
patients with subjective cognitive decline and mild cognitive impairment: findings from the 4C study. J Gerontol A Biol Sci Med Sci (2017) 72:846-54. doi:10.1093/gerona/glx003

12. Kang HG, Costa MD, Priplata AA, Starobinets OV, Goldberger AL, Peng CK, et al. Frailty and the degradation of complex balance dynamics during a dual-task protocol. J Gerontol A Biol Sci Med Sci (2009) 64:1304-11. doi:10.1093/gerona/glp113

13. Langlois F, Vu TT, Kergoat MJ, Chassé K, Dupuis G, Bherer L. The multiple dimensions of frailty: physical capacity, cognition, and quality of life. Int Psychogeriatr (2012) 24:1429-36. doi:10.1017/S1041610212000634

14. Lundin-Olsson L, Nyberg L, Gustafson Y. Attention, frailty, and falls: the effect of a manual task on basic mobility. J Am Geriatr Soc (1998) 46:758-61. doi:10.1111/j.1532-5415.1998.tb03813.x

15. McGough EL, Cochrane BB, Pike KC, Logsdon RG, McCurry SM, Teri L. Dimensions of physical frailty and cognitive function in older adults with amnestic mild cognitive impairment. Ann Phys Rehabil Med (2013) 56:329-41. doi:10.1016/j.rehab.2013.02.005

16. O’Halloran AM, Fan CW, Kenny RA, Pénard N, Galli A, Robertson IH. Variability in sustained attention and risk of frailty. J Am Geriatr Soc (2011) 59:2390-2. doi:10.1111/j.1532-5415.2011.03706.x

17. Patrick L, Gaskovski P, Rexroth D. Cumulative illness and neuropsychological decline in hospitalized geriatric patients. Clin Neuropsychol (2002) 16:145-56. doi:10.1076/clin.16.2.145.13239

18. Sargent L, Brown R. Assessing the current state of cognitive frailty: measurement properties. J Nutr Health Aging (2017) 21:152-60. doi:10.1007/ s12603-016-0735-9

19. Shimada H, Makizako H, Doi T, Yoshida D, Tsutsumimoto K, Anan Y, et al. Combined prevalence of frailty and mild cognitive impairment in a population of elderly Japanese people. J Am Med Dir Assoc (2013) 14:518-24. doi:10.1016/j.jamda.2013.03.010

20. Woollacott M, Shumway-Cook A. Attention and the control of posture and gait: a review of an emerging area of research. Gait Posture (2002) 16:1-14. doi:10.1016/S0966-6362(01)00156-4

21. Avelino-Silva TJ, Farfel JM, Curiati JA, Amaral JR, Campora F, Jacob-Filho W. Comprehensive geriatric assessment predicts mortality and adverse outcomes in hospitalized older adults. BMC Geriatr (2014) 14:129. doi:10.1186/14712318-14-129

22. Pilotto A, Ferrucci LA. A clinical definition of frailty: usefulness of the multidimensional assessment. G Gerontol (2011) 59:125-9. (Italian).

23. Sternberg SA, Bentur N. The contribution of comprehensive geriatric assessment to primary care physicians. Isr J Health Policy Res (2014) 3:44. doi:10.1186/2045-4015-3-44

24. European Innovation Partnership on Active and Healthy Ageing (EIP-AHA). A Compilation of Good Practices - Prevention and Early Diagnosis of Frailty and Functional Decline, both Physical and Cognitive in Older People. Action Group A3, European Commission (2013). Available from: https://ec.europa. eu/research/innovation-union/pdf/active-healthy-ageing/gp_a3.pdf

25. Angleman SB, Santoni G, Pilotto A, Fratiglioni L, Welmer AK; MPI_AGE Project Investigators. Multidimensional prognostic index in association with future mortality and number of hospital days in a population-based sample of older adults: results of the EU funded MPI_AGE project. PLoS One (2015) 10:e0133789. doi:10.1371/journal.pone.0133789

26. Pilotto A, Gallina P, Fontana A, Sancarlo D, Bazzano S, Copetti M, et al. Development and validation of a multidimensional prognostic index for mortality based on a standardized multidimensional assessment schedule (MPI-SVaMA) in community-dwelling older subjects. J Am Med Dir Assoc (2013) 14:287-92. doi:10.1016/j.jamda.2013.01.005

27. American Psychiatric Association (APA). Diagnostic and Statistical Manual of Mental Disorders. 5th ed. Washington, DC: American Psychiatric Association Publishing (2013).

28. Albert MS, DeKosky ST, Dickson D, Dobois B, Feldman HH, Fox NC, et al. The diagnosis of mild cognitive impairment due to Alzheimer's disease: recommendations from the National Institute on Aging-Alzheimer's Association workgroups on diagnostic guidelines for Alzheimer's disease. Alzheimers Dement (2011) 7:270-9. doi:10.1016/j.jalz.2011.03.008

29. Bruyère $\mathrm{O}$, Buckinx $\mathrm{F}$, Beaudart $\mathrm{C}$, Reginster JY, Bauer J, Cederholm T, et al. How clinical practitioners assess frailty in their daily practice: an international survey. Aging Clin Exp Res (2017) 29:905-12. doi:10.1007/s40520-017-0806-8
30. De Toni AF, Giacomelli F, Ivis S. Il mondo invisibile dei pazienti anziani. La fragilità interpretata dalla medicina di famiglia mediante la teoria della complessità. Torino, Italy: UTET Università (2010). 480 p. (Italian).

31. De Gobbi R, Fassina R, Tonon R, Benetti G. Il paziente anziano fragile: strumenti di valutazione cognitivo-funzionale in Medicina Generale. Rivista SIMG (2012) 5:14-9. (Italian).

32. Forum Ania Consumatori, CENSIS. Indagine conoscitiva sullo stato di fragilità della popolazione anziana in Italia. In: Gli scenari del welfare. editor. Verso uno stato sociale sostenibile. Milano, Italy: Franco Angeli (2015) 288. p. (Italian).

33. De Vries NM, Staal JB, Van Ravensberg CD, Hobbelen JSM, Rikkert MO, Nijhuis-Van der Sanden MWG. Outcome instruments to measure frailty: a systematic review. Ageing Res Rev (2011) 10:104-14. doi:10.1016/j.arr. 2010.09.001

34. Giordano A, Rozzini M, Trabucchi M. Frailty in elderly: a clinical view. G Gerontol (2007) 55:2-6. (Italian).

35. Pilotto A, Franceschi M, Ferrucci L. A multidimensional prognostic index (MPI) for the evaluation of the hospitalized frail older patient. G Gerontol (2007) 55:7-10. (Italian).

36. Pilotto A, Ferrucci L, Franceschi M, D’Ambrosio LP, Scarcelli C, Cascavilla L, et al. Development and validation of a multidimensional prognostic index for one-year mortality from comprehensive geriatric assessment in hospitalized older patients. Rejuvenation Res (2008) 11:151-61. doi:10.1089/rej.2007.0569

37. Pilotto A, Sancarlo D, Panza F, Paris F, D’Onofrio G, Cascavilla L, et al. The multidimensional prognostic index (MPI), based on a comprehensive geriatric assessment predicts short- and long-term mortality in hospitalized older patients with dementia. J Alzheimers Dis (2009) 18:191-9. doi:10.3233/ JAD-2009-1139

38. Gallucci M, Battistella G, Bergamelli C, Spagnolo P, Mazzuco S, Carlini A, et al. Multidimensional prognostic index in a cognitive impairment outpatient setting: mortality and hospitalizations. The Treviso Dementia (TREDEM) study. J Alzheimers Dis (2014) 42:1461-8. doi:10.3233/JAD-140516

39. Maggi S, Pilotto A. The challenge of the clinical decisions in frail multimorbid older subjects: results and recommendations from the European MPI_AGE PROJECT. International Congress of the European Union Geriatric Medicine Society; Sep 20-22; Nice, France (2017).

40. Volpato S, Bazzano S, Fontana A, Ferrucci L, Pilotto A; MPI-TriVeneto Study Group. Multidimensional prognostic index predicts mortality and length of stay during hospitalization in the older patients: a multicenter prospective study. J Gerontol A Biol Sci Med Sci (2015) 70:325-31. doi:10.1093/ gerona/glu167

41. Hughes CP, Berg L, Danziger WL, Coben LA, Martin RL. A new clinical scale for the staging of dementia. Br J Psychiatry (1982) 140:566-72. doi:10.1192/ bjp.140.6.566

42. Mioshi E, Dawson K, Mitchell J, Arnold R, Hodges JR. The Addenbrooke's cognitive examination revised (ACE-R): a brief cognitive test battery for dementia screening. Int J Geriatr Psychiatry (2006) 21:1078-85. doi:10.1002/ gps. 1610

43. Spinnler H, Tognoni G. Standardizzazione italiana e taratura di test neuropsicologici. Italian Journal of Neurological Sciences. (Vol. 6). Milano, Italy: Masson Italiana Periodici (1987). 120 p. (Italian).

44. Reitan RM, Wolfson D. A selective and critical review of neuropsychological deficits and the frontal lobes. Neuropsychol Rev (1994) 4:161-98. doi:10.1007/ BF01874891

45. De Renzi E, Vignolo LA. The token test: a sensitive test to detect receptive disturbances in aphasics. Brain (1962) 85:665-78. doi:10.1093/brain/85.4.665

46. Koren D, Seidman LJ, Poyurovsky M, Goldsmith M, Viksman P, Zichel S, et al. The neuropsychological basis of insight in first-episode schizophrenia: a pilot metacognitive study. Schizophr Res (2004) 70:195-202. doi:10.1016/j. schres.2004.02.004

47. Koren D, Seidman LJ, Goldsmith M, Harvey PD. Real-world cognitive- and metacognitive-dysfunction in schizophrenia: a new approach for measuring (and remediating) more "right stuff". Schizophr Bull (2006) 32:310-26. doi:10.1093/schbul/sbj035

48. Quiles C, Verdoux H, Prouteau A. Assessing metacognition during a cognitive task: impact of "on-line" metacognitive questions on neuropsychological performances in a non-clinical sample. J Int Neuropsychol Soc (2014) 20:547-54. doi:10.1017/S1355617714000290 
49. Amanzio M, Palermo S, Zibetti M, Leotta D, Rosato R, Geminiani G, et al. Self-unawareness of levodopa induced dyskinesias in patients with Parkinson's disease. Brain Cogn (2014) 90:135-41. doi:10.1016/j.bandc. 2014.06.014

50. Katz S, Ford AB, Moskowitz RW, Jackson BA, Jaffe MW. Studies of illness in the aged. The index of Adl: a standardized measure of biological and psychosocial function. JAMA (1963) 185:914-9. doi:10.1001/jama.1963.03060120024016

51. Lawton MP, Brody EM. Assessment of older people: self-maintaining and instrumental activities of daily living. Gerontologist (1969) 9:179-86. doi:10.1093/geront/9.3_Part_1.179

52. Logsdon RG, Gibbons LE, McCurry SM, Teri L. Assessing quality of life in older adults with cognitive impairment. Psychosom Med (2002) 64:510-9. doi:10.1097/00006842-200205000-00016

53. Hamilton M. A rating scale for depression. J Neurol Neurosurg Psychiatry (1960) 23:56-62. doi:10.1136/jnnp.23.1.56

54. Starkstein SE, Garau ML, Cao A. Prevalence and clinical correlates of disinhibition in dementia. Cogn Behav Neurol (2004) 17:139-47. doi:10.1097/ 01.wnn.0000119241.65522.90

55. Bech P, Rafaelsen OJ, Kramp P, Bolwig TG. The mania rating scale: scale construction and inter-observer agreement. Neuropharmacology (1978) 17: 430-1. doi:10.1016/0028-3908(78)90022-9

56. Amanzio M, Vase L, Leotta D, Miceli R, Palermo S, Geminiani G. Impaired awareness of deficits in Alzheimer's disease: the role of everyday executive dysfunction. J Int Neuropsychol Soc (2013) 19:63-72. doi:10.1017/ S1355617712000896

57. Starkstein SE, Jorge R, Mizrahi R, Robinson RG. A diagnostic formulation for anosognosia in Alzheimer's disease. J Neurol Neurosurg Psychiatry (2006) 77:719-25. doi:10.1136/jnnp.2005.085373

58. Migliorelli R, Tesón A, Sabe L, Petracca G, Petracchi M, Leiguarda R, et al. Anosognosia in Alzheimer's disease: a study of associated factors. J Neuropsychiatry Clin Neurosci (1995) 7:338-44. doi:10.1176/jnp.7.3.338

59. Rockwood K, Song X, MacKnight C, Bergman H, Hogan DB, Mitnitski A, et al. A global clinical measure of fitness and frailty in elderly people. CMAJ (2005) 173:489-95. doi:10.1503/cmaj.050051

60. Freund RJ, Littell RC, Spector PC. SAS System for Linear Models. 3rd ed. Cary, NC: SAS Institute Inc. (1991). $352 \mathrm{p}$.

61. Schlotzhauer SD, Littell RC. SAS System for Elementary Statistical Analysis. Cary, NC: SAS Institute Inc. (1987). 416 p.

62. Faul F, Erdfelder E, Lang AG, Buchner A. G*Power 3: a flexible statistical power analysis program for the social, behavioral, and biomedical sciences. Behav Res Methods (2007) 39:175-91. doi:10.3758/BF03193146

63. Dubois B, Feldman HH, Jacova C, Hampel H, Molinuevo JL, Blennow K, et al. Advancing research diagnostic criteria for Alzheimer's disease: the IWG-2 criteria. Lancet Neurol (2014) 13:614-29. doi:10.1016/S1474-4422(14) 70090-0

64. Petersen RC, Negash S. Mild cognitive impairment: an overview. CNS Spectr (2008) 13:45-53. doi:10.1017/S1092852900016151

65. Yassuda MS, Lopes A, Cachioni M, Falcao DV, Batistoni SS, Guimaraes VV, et al. Frailty criteria and cognitive performance are related: data from the FIBRA study in Ermelino Matarazzo, São Paulo, Brazil. J Nutr Health Aging (2012) 16:55-61. doi:10.1007/s12603-012-0003-6

66. Samper-Ternent R, Al Snih S, Raji MA, Markides KS, Ottenbacher KJ. Relationship between frailty and cognitive decline in older Mexican Americans. J Am Geriatr Soc (2008) 56:1845-52. doi:10.1111/j.1532-5415. 2008.01947.x

67. Sourial N, Bergman H, Karunananthan S, Wolfson C, Guralnik J, Payette H, et al. Contribution of frailty markers in explaining differences among individuals in five samples of older persons. J Gerontol A Biol Sci Med Sci (2012) 67:1197-204. doi:10.1093/gerona/gls084

68. Sourial N, Wolfson C, Bergman H, Zhu B, Karunananthan S, Quail J, et al. A correspondence analysis revealed frailty deficits aggregate and are multidimensional. JClin Epidemiol (2010) 63:647-54. doi:10.1016/j. jclinepi.2009.08.007

69. Bilotta C, Bergamaschini L, Nicolini P, Casè A, Pina G, Rossi S, et al. Frailty syndrome diagnosed according to the study of osteoporotic fractures criteria and mortality in older outpatients suffering from Alzheimer's disease: a one-year prospective cohort study. Aging Ment Health (2012) 16:273-80. doi:10.1080/13607863.2011.609534
70. Bilotta C, Nicolini P, Casè A, Pina G, Rossi S, Vergani C. Frailty syndrome diagnosed according to the study of osteoporotic fractures (SOF) criteria and adverse health outcomes among community-dwelling older outpatients in Italy. A one-year prospective cohort study. Arch Gerontol Geriatr (2012) 54:e23-8. doi:10.1016/j.archger.2011.06.037

71. Fougère B, Delrieu J, Del Campo N, Soriano G, Sourdet S, Vellas B. Cognitive frailty: mechanisms, tools to measure, prevention and controversy. Clin Geriatr Med (2017) 33:339-55. doi:10.1016/j.cger.2017.03.001

72. Johns EK, Phillips NA, Belleville S, Goupil D, Babins L, Kelner N, et al. The profile of executive functioning in amnestic mild cognitive impairment: disproportionate deficits in inhibitory control. J Int Neuropsychol Soc (2012) 18:541-55. doi:10.1017/S1355617712000069

73. Jekel K, Damian M, Wattmo C, Hausner L, Bullock R, Connelly PJ, et al. Mild cognitive impairment and deficits in instrumental activities of daily living: a systematic review. Alzheimers Res Ther (2015) 7:17. doi:10.1186/ s13195-015-0099-0

74. Gothe NP, Fanning J, Awick E, Chung D, Wójcicki TR, Olson EA, et al. Executive function processes predict mobility outcomes in older adults. J Am Geriatr Soc (2014) 62:285-90. doi:10.1111/jgs.12654

75. Robertson DA, Savva G, Coen RF, Kenny RA. Cognitive function in the prefrailty and frailty syndrome. J Am Geriatr Soc (2014) 62:2118-24. doi:10.1111/ jgs. 13111

76. Langner R, Eickhoff SB. Sustaining attention to simple tasks: a metaanalytic review of the neural mechanisms of vigilant attention. Psychol Bull (2013) 139:870-900. doi:10.1037/a0030694

77. Amanzio M, Torta DM, Sacco K, Cauda F, D’Agata F, Duca F, et al. Unawareness of deficits in Alzheimer's disease: role of the cingulate cortex. Brain (2011) 134:1061-76. doi:10.1093/brain/awr020

78. Espinosa A, Alegret M, Boada M, Vinyes G, Valero S, Martínez-Lage P, et al. Ecological assessment of executive functions in mild cognitive impairment and mild Alzheimer's disease. J Int Neuropsychol Soc (2009) 15:751-7. doi:10.1017/S135561770999035X

79. Espinoza SE, Jung I, Hazuda H. The Hispanic paradox and predictors of mortality in an aging biethnic cohort of Mexican Americans and European Americans: the San Antonio longitudinal study of aging. J Am Geriatr Soc (2013) 61:1522-9. doi:10.1111/jgs.12421

80. Mezuk B, Edwards L, Lohman M, Choi M, Lapane K. Depression and frailty in later life: a synthetic review. Int J Geriatr Psychiatry (2012) 27:879-92. doi:10.1002/gps.2807

81. Paulson D, Lichtenberg PA. Vascular depression: an early warning sign of frailty. Aging Ment Health (2013) 17:85-93. doi:10.1080/13607863.2012. 692767

82. Assal F, Cummings JL. Neuropsychiatric symptoms in the dementias. Curr Opin Neurol (2002) 15:445-50. doi:10.1097/00019052-200208000-00007

83. Semprini R, Lubrano A, Misaggi G, Martorana A. Apathy as marker of frail status. J Aging Res (2012) 2012:436251. doi:10.1155/2012/436251

84. Bonelli RM, Cummings JL. Frontal-subcortical circuitry and behavior. Dialogues Clin Neurosci (2007) 9:141-51.

85. Cummings JL. Anatomic and behavioral aspects of frontal-subcortical circuits. Ann N Y Acad Sci (1995) 769:1-13. doi:10.1111/j.1749-6632.1995.tb38127.x

86. Masterman DL, Cummings JL. Frontal-subcortical circuits: the anatomic basis of executive, social and motivated behaviors. J Psychopharmacol (1997) 11:107-14. doi:10.1177/026988119701100203

87. Tekin S, Cummings JL. Frontal-subcortical neuronal circuits and clinical neuropsychiatry: an update. J Psychosom Res (2002) 53:647-54. doi:10.1016/ S0022-3999(02)00428-2

Conflict of Interest Statement: The authors declare that the research was conducted in the absence of any commercial or financial relationships that could be construed as a potential conflict of interest.

Copyright () 2017 Amanzio, Palermo, Zucca, Rosato, Rubino, Leotta, Bartoli and Rainero. This is an open-access article distributed under the terms of the Creative Commons Attribution License (CC BY). The use, distribution or reproduction in other forums is permitted, provided the original author(s) or licensor are credited and that the original publication in this journal is cited, in accordance with accepted academic practice. No use, distribution or reproduction is permitted which does not comply with these terms. 